\title{
La tragedia de los bienes comunales y la escuela austriaca: Hardin, Hoppe, Huerta de Soto, y Mises ${ }^{1}$
}

\author{
PHILIPP BAGUS*
}

El objetivo de este artículo es demostrar la importancia del concepto de «tragedia de los bienes comunales» para la Escuela Austriaca, señalando su aplicabilidad al ámbito de la banca y de la democracia y subrayando los paralelismos existentes entre los dos ámbitos.

Para llevar a cabo este trabajo analizaré el término acuñado por Hardin, resaltando que si bien ha pasado a la historia como el creador del concepto «tragedia de los bienes comunales», es éste en realidad un concepto acuñado por Mises. También analizaré lo que al respecto sostiene Huerta de Soto en su análisis de la banca con reserva fraccionaria y Hoppe en su análisis de la democracia.

Además señalaré que hay una «tragedia de los bienes comunales» ideal y que hay supuestos que se acercan a este tipo ideal. Por lo tanto, mantengo que se puede usar el concepto como instrumento teórico para analizar las fuerzas e intereses inherentes a sistemas cercanos al tipo ideal.

\footnotetext{
1 Quisiera expresar mi agradecimiento a Massimiliano Neri por sus numerosos comentarios y notas, al Dr. Guido Hülsmann por impulsarme a hacer este artículo, al Dr. Rogelio Fernández Delgado y al Dr. Jesús Huerta de Soto por su extensa ayuda.

* Universidades de Münster (Alemania), y Rey Juan Carlos (Madrid). 


\section{El término y el concepto: «tragedia de los bienes comunales»}

El biólogo Garrett James Hardin² acuñó el término «tragedia de los bienes comunales». En su ahora famoso artículo de 1968 «The Tragedy of the Commons», Hardin describe cómo la propiedad comunal —es decir, el dominio público- es aprovechada hasta que se deteriora o se destruye.

Para ilustrar dicha "tragedia», es decir, la sobreexplotación de la propiedad pública, Hardin recurre a ejemplos del medio ambiente, como el de las poblaciones de peces en el océano. Pese a que los pescadores saben que la destrucción de los caladeros a largo plazo les perjudica, existe el incentivo de aprovecharse cuanto sea posible del bien común antes de que lo hagan los otros pescadores. Al final el bien común se destruye. En esto consiste la «tragedia».

Hay que subrayar que en el concepto de la tragedia de los bienes comunales de Hardin, que denominaré tipo ideal de tragedia de los bienes comunales, casi no hay obstáculos (límites) a la sobreexplotación, ${ }^{3}$ y el incentivo es explotar la propiedad común cuanto antes para cosechar el máximo lucro.

Gracias a su artículo, muchos consideran a Hardin como padre del concepto de tragedia de los bienes comunales. No obstante, en su análisis de la banca con reserva fraccionaria, Huerta de Soto ha planteado de nuevo la cuestión relativa a quién es el verdadero padre de este concepto y sostiene que Garrett Hardin no fue el primero en describirlo, sino que Ludwig von Mises ya

2 Garrett James Hardin y su esposa Jane se suicidaron el 14 de septiembre de 2003. Loa dos sufrían enfermedades graves y pertenecían al grupo End-of-Life Choices, que apoya el derecho de los pacientes a suicidarse.

${ }_{3}$ Por supuesto, un límite universal está constituido por las valoraciones subjetivas de los consumidores que pueden impedir la destrucción total de la propiedad. Es decir, el último pez en el océano probablemente nunca va a ser pescado, porque no tiene sentido económico para los pescadores incurrir en los grandes costes necesarios para buscar y capturar este último ejemplar, debido a la expectativa de obtener un precio relativamente bajo por el mismo. 
lo había descrito 28 años antes en su libro Nationalökonomie, ${ }^{4}$ de 1940.

De hecho, Mises señala en este libro que la concepción estatal de la propiedad muchas veces no es conforme a la función social de la propiedad privada. Cuando los derechos de propiedad no se definen rigurosamente, el propietario «deja de interesarse por la totalidad de los resultados de su actuación. Descuenta, en tales casos, tanto los lucros escamoteados como aquellos costes de que se le exonera». ${ }^{5}$

Más adelante Mises se centra en el problema de los costes externos que resultan de los derechos de propiedad no rigurosamente determinados. El individuo no considera los costes externos cuando emprende el cálculo económico. Por eso, el cálculo económico proporcionará resultados deficientes y falsos. Durante su discusión de los costes externos, Mises - aplicando el problema de los costes externos al medio ambiente- explícitamente describe el problema de los bienes comunales que Hardin proclamará en 1968:

Las tierras carentes de dueño efectivo (es indiferente que se considere propiedad pública desde un punto de vista meramente legal) las utiliza la gente sin preocuparse del daño que puedan sufrir. Cada cual procura lucrarse al máximo, por cualquier medio, de sus rentas -madera y caza de los bosques, riqueza piscícola de las aguas, minerales del subsuelo- desentendiéndose de los efectos que puedan producirse. La erosión de la tierra, el agotamiento de las riquezas naturales y demás quebrantos futuros son costes externos que los actores no tienen en cuenta en sus cálculos. Talan los árboles sin respetar los nuevos brotes ni pensar en repoblación alguna. Aplican métodos de caza y pesca que acaban con las crías y despueblan los lugares. ${ }^{6}$

${ }^{4}$ En el epígrafe VI del capítulo 10 de la Parte IV de Nationalökonomie: Theorie des Handelns und Wirtschaftens, Editions Union, Ginebra 1940, 2. ${ }^{a}$ ed., Philosophia Verlag, Munich 1980, pp. 599-605.

${ }^{5}$ Ludwig von Mises, (2004), p. 774.

6 Op. cit., p. 775. 
Por lo tanto, sólo se debe considerar a Garrett Hardin como padre del término, pero no del propio concepto. De hecho, como queda demostrado en el anterior pasaje, 28 años antes el concepto fue expuesto del modo más completo y sistemático por Ludwig von Mises, como parte del problema más general que plantean los derechos de propiedad insuficientemente definidos y/o defendidos. ${ }^{7}$

\section{El sistema bancario y Huerta de Soto}

La tragedia de los bienes comunales tiene una relación con la Escuela Austriaca mucho más reciente y directa. En Dinero, Crédito Bancario y Ciclos Económicos, Huerta de Soto aplica el concepto de «tragedia de los bienes comunales» a un análisis de la banca con reserva fraccionaria, es decir, al sistema bancario en el que existe un coeficiente de caja de menos del cien por cien, como ocurre en el sistema bancario moderno. ${ }^{8}$ Los bancos prestan parte del depósito a la vista a agentes económicos creando títulos de dinero ex nihilo. Esto tiene como consecuencia que los bancos no pueden reembolsar todos sus depósitos al mismo tiempo.

\footnotetext{
${ }^{7}$ Rudimentos del concepto de la «tragedia de los bienes comunales» ya se pueden encontrar en la discusión de Aristóteles sobre la propiedad privada. Aristóteles señala que la propiedad común recibe poca atención y que los propietarios impulsados por su propio interés descuidan la obligación de mantener la propiedad en buenas condiciones. Véase Rothbard (1999), p. 43.

Con Santo Tomás de Aquino el concepto entra en la escolástica: «... every man is more careful to procure what is for himself alone than that which is common to many or to all: since each one would shirk the labor and leave to another that which concerns the community, as happens where there is a great number of servants" (Summa Theologica, ed. en inglés de Benziger Brothers, Nueva York, 1947), p. 1477.

No obstante, hay que notar los diferentes puntos de vista: Aristóteles y Santo Tomás de Aquino subrayan el incumplimiento de la obligación de cuidar la propiedad común, que implica no acometer una acción que se debe hacer, mientras que Mises y Hardin se centran en la sobreexplotación activa de la propiedad pública.

8 Véase Huerta de Soto, (2002), pp. 518-21.
} 
La aplicación de Huerta de Soto merece una atención más detallada, puesto que claramente explica por qué los bancos con reserva fraccionaria, por su propia naturaleza, siempre están tentados a expandir el crédito. Además explica por qué los bancos libres con reserva fraccionaria presionan para la introducción de un banco central.

Como señala Huerta de Soto, el problema de la tragedia de los bienes comunales surge siempre que se definen los derechos de propiedad inadecuadamente. En el caso de la banca con reserva fraccionaria, los banqueros pueden violar los derechos de propiedad porque no está definido claramente quién es el propietario del depósito. Cuando los clientes efectúan sus depósitos, el banco promete que el depósito siempre estará disponible para ser retirado. Sin embargo, los depósitos - por la propia definición de la banca con reserva fraccionaria- nunca están disponibles para todos los clientes en un mismo momento. Esto es así porque los bancos disponen de una parte de estos depósitos y la prestan a otros clientes. Es decir, emiten medios fiduciarios. ${ }^{9}$ Los bancos violan los principios tradicionales del derecho de propiedad de sus depositantes cuando emiten más títulos de propiedad que la propiedad que tienen confiada. ${ }^{10}$ Cuando los bancos violan y abusan de los derechos de propiedad de sus clientes obtienen grandes beneficios. La tentación de expandir el crédito es casi irresistible. Además, intentarán expandir el crédito y emitir medios fiduciarios tanto como les sea posible sin que ello les perjudique.

Esta expansión crediticia presenta otro rasgo típico que se puede encontrar en la tragedia de los bienes comunales en relación con los costes externos. En este caso, todos resultan perju-

\footnotetext{
${ }^{9}$ Los medios fiduciarios son el exceso de los títulos monetarios «que sobrepasa la cuantía de las reservas». Mises (2001) p. 519.

10 Huerta de Soto, op. cit., p. 518. Una de las más importantes contribuciones de este exhaustivo libro es demostrar cómo se ha desarrollado históricamente la banca y que la banca con reserva fraccionaria evolucionó como una perversión del derecho de propiedad tradicional.
} 
dicados por los cambios en los precios inducidos por la emisión de los medios fiduciarios. Estos costes externos negativos no son tenidos en consideración por los bancos, quienes intentan explotar las oportunidades de ganancia ofrecidas por un sistema legal que ni determina ni defiende apropiadamente los derechos de propiedad de sus depositantes.

Explotación y costes externos son rasgos similares en el análisis de Hardin de la tragedia de los bienes comunales aplicados al medio ambiente y en el análisis de Huerta de Soto aplicado a la banca libre con reserva fraccionaria. Sin embargo, como Huerta de Soto señala, existe una diferencia importante entre los dos. En el análisis de Hardin no existe prácticamente límite alguno a la explotación de lo «no privatizado», por ejemplo, la propiedad medioambiental no claramente definida. Sin embargo, en relación con los bancos con reserva fraccionaria sí que existe un límite importante en la emisión de medios fiduciarios a costa de los clientes del banco. Este límite viene impuesto por el comportamiento de los otros bancos y de sus depositantes en un sistema de banca libre. En concreto, la expansión crediticia está limitada porque los bancos pueden verse forzados a la quiebra por el sistema de liquidación de las cámaras de compensación interbancaria.

Imaginémonos un simple ejemplo. Hay dos bancos: banco A y banco $\mathrm{B}$. El banco A expande el crédito mientras que el banco B no lo hace. Los títulos de dinero emitidos por el banco A son intercambiados por clientes del banco A con clientes del banco B. En un determinado momento, los clientes del banco B o el propio banco B reclamarán la amortización de los títulos de dinero al banco A. Por ello, el banco A perderá algunas de sus reservas, por ejemplo oro. Como cualquier banco con reserva fraccionaria, el banco A puede verse abocado a la suspensión de pagos. Es decir, no puede amortizar todos los títulos de dinero que ha emitido. Por lo tanto, si el banco B y sus clientes reclaman que el banco A amortice los títulos de dinero hasta el punto en 
que no pueda cumplir, el banco A tiene que suspender pagos (y, eventualmente, declarar su quiebra).

De ahí que el sistema de liquidación y los clientes de los restantes bancos, al reclamar la amortización de sus títulos, pongan estrechos límites a la emisión de los medios fiduciarios. Los bancos tienen un cierto incentivo a restringir la expansión de medios fiduciarios en un grado más estricto que sus bancos rivales con el objetivo final de forzar a sus competidores a la quiebra y quedarse solos en el mercado. Es decir, estos bancos por supuesto que quieren explotar las grandes oportunidades de ganancia ofrecidas por los inadecuadamente definidos derechos de propiedad; sin embargo, sólo pueden expandir el crédito mientras puedan evitar razonablemente el riesgo de suspensión de pagos y quiebra. Es decir, la competencia les obliga a controlar su expansión crediticia.

El problema que ahora se plantea es cómo pueden los bancos incrementar sus beneficios con la expansión crediticia mientras mantienen un riesgo de quiebra bajo. La solución obviamente radica en llegar a acuerdos para evitar las consecuencias negativas de una expansión crediticia independiente y no coordinada. Por eso, los bancos tienden a establecer una política combinada, simultánea y simétrica, de expansión crediticia. Esta política les permite mantener su solvencia, guardar sus reservas, y obtener grandes ganancias.

Por tanto, la tragedia de los bienes comunales no sólo predice la explotación y los costes externos de una propiedad privada vagamente definida, sino que también explica por qué hay grandes fuerzas en un sistema de banca libre que impulsan la realización de acuerdos empresariales, fusiones y cárteles. Sin embargo, incluso después de la fundación de un cártel, la amenaza de quiebra sigue latente. El cártel bancario, como todos los cárteles, es inestable. Por eso los bancos de reserva fraccionaria tienen un gran incentivo para pedir la creación de un banco central. La única diferencia entre la tragedia de los bienes comu- 
nales aplicada al medio ambiente y aplicada al sistema de la banca libre - los límites en la explotación- es ahora eliminada por la introducción de un banco central. Por lo tanto, una verdadera situación de tragedia de los bienes comunales se encuentra sólo, según Huerta de Soto, cuando el banco central ha sido establecido. Ahora los bancos pueden explotar sin restricción la propiedad incorrectamente definida y malamente defendida.

Sin embargo, incluso en el escenario más favorable para los bancos, esto es, cuando el banco central y el papel moneda han sido creados, existe un límite que Huerta de Soto no menciona: el riesgo de la hiperinflación. Como Rothbard expone, «with fiat money established and gold outlawed, the way is clear for full-scale... inflation. Only one very broad check remains: the ultimate threat of hyper-inflation, the crack up of the currency.» ${ }^{11}$

Por lo tanto, hay que concluir que la analogía de Huerta de Soto que relaciona la banca con reserva fraccionaria con la tragedia de los bienes comunales no es totalmente perfecta.

Es decir, incluso cuando se ha creado un banco central, aún existe un control a la explotación de la propiedad privada. En una situación de tragedia de los bienes comunales ideal, el incentivo consiste en explotar la mal definida propiedad tan rápido como sea posible para adelantarse a la posible explotación de otros. Sin embargo, incluso cuando existe un banco central que asegure su solvencia, no les conviene a los bancos con reserva fraccionaria emitir los medios fiduciarios tan rápido como les sea posible. Hacer esto podría conducir a una hiperinflación sin freno. ${ }^{12}$ Esta hiperinflación llevaría al colapso del sistema mone-

11 Véase Murray N. Rothbard, What Has Government Done to Our Money (5. a ed., Auburn, Ala.: Ludwig von Mises Institute, pdf. Edición online), p. 43.

12 Hay otro límite a la expansión crediticia que viene impuesto por la opinión pública. Ésta puede influir en el comportamiento del banco central induciéndole a mantener la expansión crediticia dentro de ciertos límites. Este es el motivo por el cual los bancos centrales dedican muchos esfuerzos a construir su credibilidad frente a la opinión pública. 
tario y a tensiones sociales que no redundarían en beneficio del sistema bancario.

Hay que subrayar que la hiperinflación es un fenómeno que depende de la «opinión pública», o mejor dicho de las expectativas del público. Es decir, los individuos creen que la inflación continuará en el futuro y se deshacen de su dinero con rapidez impulsando así la pérdida de poder adquisitivo y reforzando la inversión en «valores reales». La explotación de los bienes comunales, por lo tanto, tiene que ser diluida y llevarse a cabo con cuidado. No obstante, la analogía de Huerta de Soto es muy útil para comprender los incentivos, la dinámica y la naturaleza de un sistema de banca con reserva fraccionaria.

\section{La democracia y Hoppe}

Otra relación importante entre la escuela austriaca y la tragedia de los bienes comunales se puede encontrar en el análisis que Hoppe hace de la democracia. Hoppe señala que la combinación de la regla de «una persona-un voto» con el acceso libre al gobierno democrático para cada persona adulta implica que cada persona y su propiedad están al alcance y a disposición de la mayoría. Es decir, se crea así una situación de tragedia de los bienes comunales. ${ }^{13}$

Hoppe no profundiza en esta idea y no subraya los límites que existen a la explotación de la propiedad mal definida en esta situación. No obstante, merece la pena investigar los posibles límites de explotación para entender mejor las fuerzas que actúan en los procesos democráticos.

De hecho, en democracia los derechos de propiedad no se encuentran rigurosa y establemente determinados porque el propio Estado, como monopolio de compulsión y coerción,

${ }^{13}$ Véase Hans-Hermann Hoppe (2004). 
puede redefinir y cambiar los derechos de propiedad en cualquier momento. Es decir, no se garantiza una definición clara, segura y estable de los derechos de propiedad.

Existe el incentivo para el ser humano, siempre impulsado por su propio interés, de usar el libre acceso al gobierno y la regla «una persona-un voto» para explotar y expropiar la propiedad privada de los demás. En las democracias modernas se suele explotar la propiedad privada mediante impuestos, regulaciones, la prestación de servicios para el Estado y la confiscación inflacionaria. En otras palabras, en democracia cualquier individuo puede acceder al gobierno y una vez en el gobierno expropiar la propiedad de los demás con impuestos, etc.

Además, en democracia se cumple otra característica de la tragedia de los bienes comunales: dada la limitación temporal del gobierno democrático, existe, en contraste con la monarquía, un incentivo a explotar la propiedad privada cuanto antes, porque si no se aprovecha esta oportunidad ahora, el próximo y posiblemente distinto gobierno lo hará.

No obstante, igual que sucede en el caso de la banca con reserva fraccionaria, la analogía con la tragedia de los bienes comunales en el medio ambiente, es decir, la tragedia de los bienes comunales ideal, no es perfecta, porque hay límites a la explotación de los derechos de propiedad. E igual que sucedía en el caso de la banca con reserva fraccionaria, estos límites pueden explicar la tendencia en las democracias a suprimir dichos límites en la medida en que sea posible. Existen dos límites fundamentales a la explotación de la propiedad no rigurosamente definida en una democracia: la competencia de otros Estados y la opinión pública.

El primer límite está constituido por la competencia de otros Estados. Las democracias con impuestos más bajos y menos regulaciones impulsan a que la población de otros Estados más intervenidos emigre hacia ellas, por lo que se produce una transferencia de propiedad hacia los Estados menos expropia- 
dores. Se podría decir que, análogamente a lo que ocurría en el caso de la banca con reserva fraccionaria, los Estados se hallan también en peligro de perder sus «reservas», proporcionadas por los bienes de los ciudadanos objeto de expropiación estatal. La solución para las democracias, o los Estados en general, para superar este límite es análoga a la del caso de la banca libre con reservas fraccionarias: la formación de acuerdos, cárteles y fusiones para «armonizar» la competencia entre sí y orquestar una expropiación simultánea y más intensa de la propiedad de los particulares. ${ }^{14}$ Como los cárteles y los acuerdos libres no son estables, han de vincular a las partes de manera legal. Por eso los Estados tienen el incentivo de establecer entre ellos vínculos de tipo jurídico. Un ejemplo histórico muy ilustrativo de esta evolución hacia una «armonización» legislativa y la formación de una constitución está representado por la propia Unión Europea.

Además, existe una opción más violenta y frecuentemente usada para impedir la competencia de otros Estados y así ampliar la base de propiedad privada que puede ser expropiada y que, por supuesto, no existe en el caso de la banca con reserva fraccionaria: la guerra. Irónicamente, se ha utilizado el miedo a la guerra, la táctica más violenta para eliminar el límite que supone la competencia, para justificar la técnica de la «armonización». De hecho, después de la Segunda Guerra Mundial se argumentaba a favor de una unión europea para evitar el riesgo de una nueva guerra intraeuropea. ${ }^{15}$ En suma, los dos, guerra y «armonización», sirven para deshacerse de la competencia entre Estados.

14 Por supuesto, esta tendencia se ve frenada por el problema que plantea la cesión del poder existente antes de la unión, alianza o federación de Estados, dado que implica la renuncia parcial a la propia soberanía. Hülsmann argumenta que los inconvenientes de la unificación pueden llegar a ser irrelevantes ante el miedo a la extensión de «quiebras» estatales. Véase Hülsmann (1997), pp. 81-96.

15 Por ejemplo, Helmut Kohl, canciller alemán, argumentaba así. Véase Hoppe (ed.), (2003), p. 169. 
El segundo límite más fundamental a la expropiación, es el de la opinión pública, que pone una limitación en dos sentidos. Primero, la opinión pública es esencial para todos los Estados, porque el poder es «un fenómeno moral y espiritual». «Un sistema duradero de gobierno debe basarse siempre en una ideología que la mayoría acepte.» ${ }^{16}$ Es decir, el gobierno democrático tiene que convencer a la mayoría de que la expropiación de la propiedad privada es en su propio interés o al menos legítima. ${ }^{17}$ Una táctica apropiada para lograrlo consiste en generar confusión sobre quién resulta ganador neto y quién resulta perdedor neto de las redistribuciones democráticas. Por eso es esencial para el gobierno promocionar la ideología democrática que mantiene, entre otros aspectos, que la expropiación de la propiedad privada llevada a cabo por un gobierno elegido democráticamente es siempre legítima. Quizás una de las razones del éxito de la democracia consista precisamente en que es más fácil convencer a la mayoría de la población de que la explotación de la propiedad privada por el Estado es legítima si es que se efectúa democráticamente.

Además, la opinión pública establece un límite importante a la explotación de la propiedad privada: en las democracias los políticos desean, ante todo, ser reelegidos. Es decir, el gobierno no sólo tiene el incentivo de convencer a la mayoría de la población de que la explotación de la propiedad es legítima, sino también de que, al menos el día de la elección, es mejor que la expropiación siga en sus manos en vez de en las manos del partido opositor.

La solución para reducir, al menos, el límite de la expropiación de los derechos de propiedad, constituido por la opinión pública consiste obviamente en influir, modelar y formar la

16 Véase Mises, (2001) pp. 226 y 227.

17 Algunas veces puede ser conveniente convencer a la mayoría de la población de la necesidad de cambiar o interpretar de diferente modo determinadas barreras institucionales, constituidas por las leyes o las constituciones. 
opinión pública para acercarse a una situación de tragedia de los bienes comunales ideal, que es la situación más confortable para los gobernantes. Por eso habitualmente el Estado controla e influye en la opinión pública a través de la educación, es decir, de las escuelas, institutos, colegios y universidades públicas y privadas. Además, juega un papel importante en los medios de comunicación a través de numerosos controles, regulaciones, medios públicos, censura y licencias de los medios.

En resumen, la analogía de la democracia con la tragedia de los bienes comunales ideal no es perfecta, pero, como sucedía en el caso de la banca con reserva fraccionaria, puede explicar muchas tendencias existentes que determinan el comportamiento de los gobiernos democráticos que tratan de remover los límites a la expropiación de la propiedad privada mal definida y defendida por el propio sistema político.

\section{Conclusión}

Hay que subrayar los interesantes paralelismos existentes en el análisis de la banca con reserva fraccionaria y el análisis de la democracia con la teoría de la tragedia de los bienes comunales. En ambos casos la analogía con la tragedia de los bienes comunales en el medio ambiente no es perfecta, porque en la «tragedia ideal» no hay límites a la explotación de la propiedad no rigurosamente definida y el incentivo es el explotar esta propiedad cuanto antes para adelantarse a la explotación efectuada por los demás.

Por el contrario, en los casos de la banca con reserva fraccionaria y de la democracia si hay límites a la explotación que son muy incómodos para los individuos que quieran disfrutar libremente de la explotación de la propiedad no definida adecuadamente. Por eso, en los dos casos existen incentivos para eliminar dichos límites siempre que sea posible, sin que se pueda llegar a una situación de tragedia ideal. Además, los límites son 
muy parecidos y en los dos casos están constituidos por los dos pilares de la competencia y la opinión pública.

Por lo tanto, el concepto de tragedia de los bienes comunales de tipo ideal, o bien, de tipo hardiano, puede servir como instrumento teórico para analizar en la realidad sistemas con derechos de propiedad mal definidos que están cerca de este tipo ideal, pero que están restringidos por determinados límites, y para entender, asimismo, aquellas fuerzas e intereses inherentes a los propios sistemas que tratan de superar dichos límites, aproximándose de este modo al supuesto ideal de «tragedia».

En suma, se puede concluir que el concepto y el término de tragedia de los bienes comunales constituyen en una contribución importante de la Escuela Austriaca. Mises expuso el fundamento teórico del concepto antes y de forma más completa que Hardin. Basándose en esta teoría, Huerta de Soto desarrolla su análisis de la banca con reserva fraccionaria para explicar las fuerzas inherentes en este sistema para crear un banco central, y Hoppe impulsa con su analogía de la tragedia de los bienes comunales y la democracia un análisis paralelo en el campo político. 


\section{REFERENCIAS BIBLIOGRÁFICAS}

HARDIN, G., «La tragedia de los communes», en Enciclopedia Fortune de Economía (Barcelona: Ediciones Folio, 1998).

Hoppe, H.-H., Democracy - The God That Failed (New Brunswick, NJ y Londres: Transaction Publishers, 3. ${ }^{\mathrm{a} e d .,}$ 2002). Traducción española: Monarquía, democracia y orden natural (Madrid: Ediciones Gondo, 2004).

Hoppe, H.-H. (ed.), The Myth of National Defense: Essays on the Theory and History of Security Production (Auburn, Ala: Ludwig von Mises Institute, 2003).

HÜLSMANN, G., «Political Unification: A Generalized Progression Theorem», en Journal of Libertarian Studies 13:1 (Verano 1997).

HUERTA DE SOTO, J., Dinero, crédito bancario y ciclos económicos (Madrid: Unión Editorial, 2. ${ }^{a}$ ed., 2002).

VON MisES, L., La acción humana (Madrid: Unión Editorial, 7. a ed., 2001).

RothbARD, Murray N., Historia del pensamiento económico, vol. I (Madrid: Unión Editorial, 1999).

Rothbard, Murray N., What Has Government Done to Our Money (Auburn, Ala.: Ludwig von Mises Institute, 5. ${ }^{a}$ ed. pdf. Edición online). 